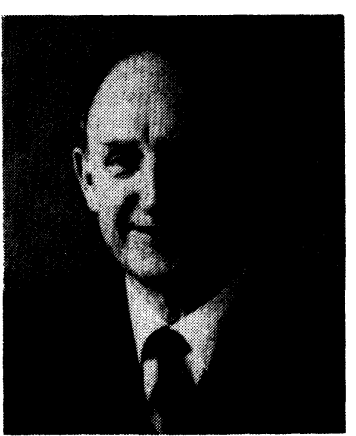

\section{The Logical Place to Publish}

The Society has had a journal since 1962 . Initially it was just called the SPIE Journal and we published bimonthly from 1962 until 1970. In 1970, the journal changed its name to Optical Engineering and continued to publish bimonthly until 1986 when it became a monthly journal.

In developing a recent poster about our journal for the San Diego meeting held in July, the editor and staff of Optical Engineering considered the message we would like to convey to our current and prospective authors. The essence of that message, and the goal we aspire to as a journal, is conveyed in these words:

Timely and authoritative...

The logical place to publish.

Our message to authors goes on to include statements covering the journal's purpose and submission policy:

“Optical Engineering publishes original papers reporting on the research and development of new optical technology or the practical application of knownoptical technology in new and inventive ways.

“Optical Engineering welcomes submission of proceedings papers, provided those papers have been revised to meet journal standards and are submitted in a format necessary for consideration by the editor and reviewers."

The editor and staff of Optical Engineering recognize your concerns and expectations as authors and therefore make the following pledges:
- Reach the right audience.

Each monthly issue reaches more than 12,000 professionals in optical science and engineering and nearly 1000 institutions and libraries worldwide.

- Timely publication.

Your papers are peer-reviewed in about three months and are normally published within three to six months of acceptance.

- High technical and editorial standards.

Papers are published only after they are recommended by at least two referees and meet our standards for technical originality and clarity of presentation.

- Widely indexed and cited.

Optical Engineering is indexed by Current Contents, INSPEC, Engineering Information, Chemical Abstracts, and other citation databases.

- Your needs as an author are given professional attention.

Your papers receive the technical and editorial care they deserve and are presented in print accurately and clearly.

As your editor, and with the cooperation of authors and reviewers, we expect to meet these goals for our journal.

Brian J. Thompson

Editor 
November 1991

Infrared Imaging Systems

Mohammad A. Karim

University of Dayton

Center for Electro-Optics

Dept. of Electrical Engineering

300 College Park Ave.

Dayton, OH 45469-0226

$513 / 229-3611$

\section{January 1992}

Smart Materials and Structures

Richard O. Claus

Virginia Polytechnic Institute and

State University

Dept. of Electrical Engineering

Fiber and Electro-Optics Research Center

648 Whittemore Hall

Blacksburg, VA 24061

703/231-4580

\section{March 1992}

Optics in Poland

Romuald Jozwicki

Warsaw Institute of Technology

Institute of Design of Precision and Optical

Instruments

ul. Chodkiewicza 8

02-525 Warsaw, Poland

\section{April 1992}

Optical Methods and Means of Information Processing

Mikhail M. Miroshnikov

S.I. Vavilov State Optical Institute

199034, Birjevaya Liniya 12

Leningrad, USSR

\section{May 1992}

Optical Implementation of Information

Processing, Pattern Recognition, and Neural

Networks

Bahram Javidi

University of Connecticut

Department of Electrical and

Systems Engineering

Room 312, U-157

260 Glenbrook Road

Storrs, CT 06269-3157

203/486-2867

203/486-0318 FAX

This special issue will cover: optical information processing, including linear and nonlinear operations and transforms; pattern recognition, correlation, filters, distortion invariant object identification; applications of holography in information processing; feature extraction and classification; associative processors and neural networks; and applications of spatial light modulators in $1-D$ and $2-D$ information processing.
June 1992

Adaptive Signal Processing

Simon Haykin

McMaster University

Communications Research Laboratory

1280 Main Street West

Hamilton, Ontario L8S 4K1 Canada

416/525-9140

This special issue will cover the following areas: historical perspective of adaptive signal processing, fast algorithms for adaptive filtering, blind deconvolution, chaotic models, wavelet transforms, and neural networks. The emphasis will be on theor and applications.

\section{August 1992}

Optical Engineering and U.K. Industry

Lionel R. Baker

Sira Led.

South Hill, Chislehurst

Kent BR7 5EH, United Kingdom

+44814672636

+4481467 6515 FAX

R. J. Parker

Rolls Royce plc

P.O. Box 31

Derby DE2 8BJ, United Kingdom

This special issue will represent a typical cross section of current applied research taking place in the United Kingdom in the field of optics. We invite those who would like to submit manuscripts to notify L. R. Baker of the title and principal author as soon as possible. Those papers that receive provisional acceptance will begin the refereeing process in early September 1991.

We regard this as an excellent opportunity to promote the best in U.K. optics research worldwide and sincerely hope you will be among those able to offer a title for consideration by our Papers Committee

\section{October 1992}

\section{Acousto-Optics}

Ting-Chung Poon

Virginia Polytechnic Institute and State University

Bradley Department of Electrical Engineering

Optical Image Processing Laboratory

Blacksburg, VA 24061

703/231-4876

703/231-3362 FAX

This special issue will focus on all aspects of research on acousto-optic effects and devices as well as their signal and image processing applications. Manuscripts should be sent to Ting-Chung Poon before February 1, 1992.

\section{December 1992}

\section{Automatic Target Recognition}

Firooz Sadjadi

Systems and Research Center

Honeywell Inc.

3660 Technology Drive

Minneapolis, MN 55418

612/782-7543

612/782-7438 FAX

The areas to be considered for inclusion are sonar. radar, laser and passive IR, visible ATR techniques, modeling of sensors, target segmentation, detection, and tracking, model-based iarget recognition, multisensor processing and sensor fusion for ATR role of performance evaluation in ATR, invarian object recognition, neural networks for ATR, adaptive and learning systems for ATR, and optical processing for ATR.

Authors are invited to submit manuscripts on any of the above topics. Manuscripts should be sent to Firooz Sadjadi before April 1, 1992.

\section{January 1993}

\section{Optical Research in Asia}

Chung J. Kuo

National Chung Cheng University

Department of Electrical Engineering

Chiayi, Taiwan 62107

886-5-226-3410, ext. 6210

886-5-226-3435 FAX

Toshimitsu Asakura

Hokkaido University

Research Institute of Applied Electricity

Sapporo, 060 Japan

81-11-716-2111

81-11-758-3173 FAX

Yong H. Lee

Korea Advanced Institute of Science

and Technology

Department of Physics

Yusung-Ku, Taejon, Korea

82-42-829-2536

82-42-861-1458 FAX

This special issue will present innovative research and development results from Asian countries. Every field of photonics will be considered. Prospective authors are invited to submit manuscripts for consideration. Manuscripts should be received by Chung J. Kuo, Toshimitsu Asakura, or Yong H. Lee before February 1, 1992.

March 1993

Optical Fiber Reliability II

Hakan H. Yuce

Belloore

445 South Street

Morristown, NJ 07962

201/829-4945

201/267-9753 FAX

Charles R. Kurkjian

AT\&T Bell Laboratories

600 Mountain Avenue

Murray Hill, NJ 07960-1910

908/582-2378

908/582-2783 FAX

July 1993

Visual Communication and Image

Processing IV

Kou-Hu Tzou

Bellcore

Room NVC 3B-311

331 Newman Springs Road

Red Bank, NJ 07701-7040

908/758-2857

908/758-0889 FAX 